\title{
Analysis of Mechanical Characteristics of Mountain Highway Section Surface Structure Based on Load
}

\author{
Zhang Zhigang ${ }^{1}$, Wang Yue ${ }^{2,}$, Wang Wei ${ }^{2}$, Qiao Jiangang ${ }^{2}$ \\ ${ }^{1}$ He Bei Expressway Group Limited YanChong Preparatory Office, Shijiazhuang, China \\ ${ }^{2}$ School of Civil and Transportation Engineering, Hebei University of Technology, Tianjin, China \\ Email address: \\ Zhangzg369@126.com (Zhang Zhigang),582183785@qq.com (Wang Yue), 1055069099@qq.com (Wang Wei), \\ Qiaojg369@126.com (Qiao Jiangang) \\ ${ }^{*}$ Corresponding author
}

\section{To cite this article:}

Zhang Zhigang, Wang Yue, Wang Wei, Qiao Jiangang. Analysis of Mechanical Characteristics of Mountain Highway Section Surface Structure Based on Load. Science Discovery. Vol. 9, No. 5, 2021, pp. 219-225. doi: 10.11648/j.sd.20210905.14

Received: September 10, 2021; Accepted: September 29, 2021; Published: October 19, 2021

\begin{abstract}
Mountain roads have many kinds of diseases due to their special natural and geographical conditions, and it is difficult to maintain the road surface, so it is particularly important to analyze the causes of the diseases from the theoretical aspect, in order to explore the relationship between structural mechanical characteristics and load of mountain highway pavement, the finite element simulation method was used to study the compressive stress, structural layer displacement, compressive strain, transverse shear stress, longitudinal shear stress, and longitudinal shear of different pavement structure layer depths under load. Change trend of strain. The results show that the compressive stress, longitudinal shear stress, and transverse shear stress are mainly concentrated in the surface layer and have a relatively large impact on the surface layer; the displacement value, compressive strain, and longitudinal shear strain are larger in the surface layer, and the compressive strain and longitudinal shear strain are at the joint Sudden change occurs; as the load increases, the pavement displacement, compressive stress, longitudinal shear stress, compressive strain, longitudinal shear strain, and transverse shear stress of each structural layer gradually increase, the overall structure of the pavement changes, and the probability of road damage increases. It can be seen that the changes in mechanical characteristics of asphalt pavement under different loads and different depths provide a new research idea for mountain highway pavement protection.
\end{abstract}

Keywords: Mountain Highway Pavement, Finite Element Analysis, Displacement, Stress, Strain

\section{基于荷载作用的山区路段面层结构力学特性分析}

\author{
张志刚 ${ }^{1}$ ，王月 ${ }^{2 *}$ ，王伟 ${ }^{2}$ ，乔建刚 ${ }^{2}$ \\ 1河北高速公路集团有限公司延崇筹建处, 石家庄, 中国 \\ 2河北工业大学土木与交通学院, 天津, 中国
}

邮箱

Zhangzg369@126.com（张志刚），582183785@qq.com（王月）, 1055069099@qq.com（王伟）, Qiaojg369@126.com（乔建刚）

\begin{abstract}
摘要: 山区公路由于其特殊的自然及地理条件导致病害种类繁多,路面的维护较为困难, 从理论方面分析病害发生原因 尤为重要, 为探究山区公路路面的结构力学特征与荷载之间关系, 利用有限元模拟方法研究了在荷载作用下不同路面 结构层深度的压应力、结构层位移、压应变、横向剪应力、纵向剪应力、纵向剪应变变化趋势。结果表明：压应力、 纵向剪应力、横向剪应力主要集中在面层, 对面层影响相对较大; 位移值、压应变、纵向剪应变在面层较大, 压应变、 纵向剪应变在联结处发生突变; 随着荷载增大，各结构层的路面位移、压应力、纵向剪应力、压应变、纵向剪应变、 横向剪应力逐渐增加，路面整体结构受力发生变化，路面发生病害的概率增加。可见，励青路面在不同荷载作用下、 不同深度下的力学特性变化情况, 为山区公路路面防护提供了一种新的研究思路。
\end{abstract}


关键词: 山区公路路面, 有限元分析, 位移, 应力, 应变

\section{1. 引言}

鉴于山区公路路面鼓包、车辙等病害严重影响道路安 全行车, 研究公路路面力学结构可以提高广大学者、工程 技术人员对路面力学特性的认识, 同时, 为路面结构防护 等工程实践提供理论基础。

近年来, 国内外诸多学者在沥青路面病害防治方面提出 诸多成果。国外学者利用有限元模拟及建模研究路面病害形 成机理 [1-5], 通过现场实验验证山区道路在荷载下的应力变 化 [6-7]。国内李海滨等人改变半刚性基层和沥青面层的厚度 和模量, 从而改善路面结构层受力, 增强半刚性基层在高等 级路面结构中的适应性[8]。周正峰等人利用有限元模型提出 柔性沥青路面路基工作区深度判定标准, 并且工作区深度随 路基模量的增加而增加[9]。王志红等人利用有限元模拟, 研 究了无机结合料、沥青结合料稳定类基层路面结构, 提出最 大剪应力在路表 $2 \mathrm{~cm}$ 范围内重载交通条件下选用无机结合料 稳定类基层沥青路面结构[10]。阮鹿鸣提出较厚的沥青层能 够改善基层开裂、路基永久变形、沥青层疲劳开裂和抗剪破 坏等病害[11]。王浩等人利用正交试验方法设计多种路面结 构组合方案, 对各层总变形和沥青层底弯拉应变进行计算, 对各参数进行敏感性分析, 得出相对合理的路面结构组合形 式[12]。贾晓东等人依托天水高速公路试验段, 研究沥青路 面在受水影响和不受水影响下的疲劳寿命, 为沥青路面在结 构设计考虑水、温度及车辆作用等影响因素, 提供了参考依 据[13]。桑伟利用有限元分析法, 分析长大纵坡路面在不同 坡度、车速及不同超载率条件下的受力状态, 分析不同因素 下最大剪应力的变化特征[14]。范永根等人利用强度折减法 构建了沥青路面有限元模型, 研究了高温、重载以及二者耦 合作用下路面应力分布状况, 结果表明二者耦合作用下更易 导致车辙等剪切破坏 [15]。周陶宏利用ANSYS软件分析沥青 路面在轴载作用下的路表弯沉、压应力、拉应力, 分析路面 结构的损伤情况[16]。

综上所述, 以往研究成果对山区轴载、路面结构层深 度与路面的压应力、结构层位移、压应变、横向剪应力、 纵向剪应力、纵向剪应变的综合研究报道相对较少, 本文 拟利用有限元分析法探究了不同轴载、不同深度对路面的 结构力学特性的影响, 为山区路面防护提供新的研究思路。

\section{2. 山区公路沥青路面有限元模型}

\section{1. 路面结构与材料特性}

以某二级山区公路路面结构为研究对象, 该路面 结构主要分为五个结构层, 即上面层、下面层、基层、 底基层、土基层。每个结构层所用材料及材料参数如 表1所示。公路路面结构层分布情况如图1所示。其中, 深度 $0 \mathrm{~cm} 、 4 \mathrm{~cm} 、 10 \mathrm{~cm} 、 50 \mathrm{~cm} 、 70 \mathrm{~cm}$ 分别代表上面层 层顶、下面层层顶、基层层顶、底基层层顶、土基层 层顶。
表1 道路各结构层参数。

\begin{tabular}{llllll}
\hline 结构层 & 结构层材料 & $\begin{array}{l}\text { 结构层厚 } \\
\text { 度/(cm) }\end{array}$ & $\left.\begin{array}{l}\text { 密度 } \\
\text { /(kg·m }\end{array} \mathbf{k n}^{-3}\right)$ & $\begin{array}{l}\text { 回弹模量 } \\
\text { /(MPa) }\end{array}$ & 泊松比 \\
\hline 上面层 & $\mathrm{AC}-13$ & 4 & 2200 & 1400 & 0.25 \\
下面层 & $\mathrm{AC}-20$ & 6 & 2100 & 1200 & 0.25 \\
基层 & 水泥稳定碎石 & 40 & 2100 & 1400 & 0.20 \\
底基层 & 级配碎石 & 20 & 1900 & 700 & 0.35 \\
土基层 & - & - & 1800 & 50 & 0.40 \\
\hline
\end{tabular}

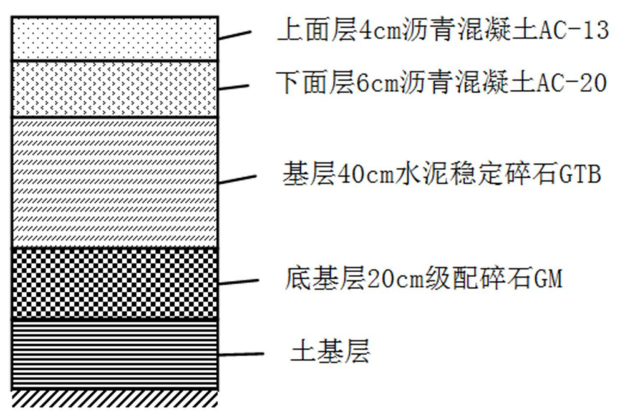

图1 各结构层厚度及路面结构层示意图。

\section{2. 路面荷载参数设定}

沥青路面结构设计时以双轮组单轴载 $100 \mathrm{KN}$ 为标准 轴载, 对应轮胎接地压强为 $0.7 \mathrm{MPa}$, 为更加真实反映车辆 行驶过程路面受力状况, 荷载设置为动态荷载。为了便于 建模分析, 将车轮作用区域等效换算为边长为 $0.266 \mathrm{~m}$ 的矩 形荷载作用区域, 假定车辆爬坡速度为 $30 \mathrm{~km} / \mathrm{h}$, 则轮胎作 用时间约为 $0.03 \mathrm{~s}$ 。因此荷载形式采用峰值为 $0.7 \mathrm{MPa}$, 持 续时间为 0.03 秒的半周期正弦曲线动态荷载。

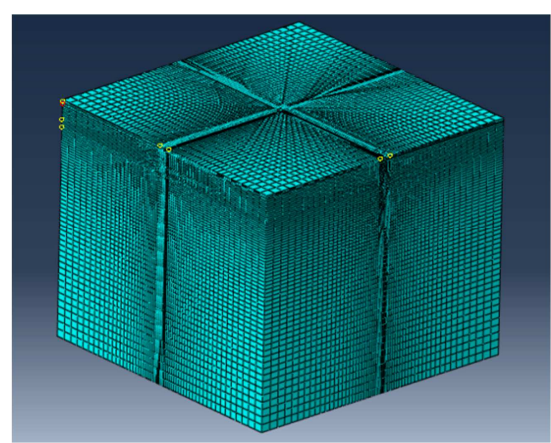

图2 山区公路载荷作用区域的网格划分。

由于山区公路货车流量较大, 货车载货量较大, 荷载较 重, 因此, 山区公路要承担较大载重量, 我国标准轴载为 $100 \mathrm{KN}$, 而我国交通运输部规定公路管理机构不允许山区公 路行驶最大轴载超过 $20000 \mathrm{~kg}$ 的可多轴多轮液压平板车。所 以, 设定 $200 \mathrm{KN}$ 为轴载上限, 设定 $100 \mathrm{KN}$ 为基础, 轴载变量 分别为 $100 \mathrm{KN} 、 120 \mathrm{kN} 、 140 \mathrm{kN} 、 160 \mathrm{kN} 、 180 \mathrm{kN} 、 200 \mathrm{kN}$ 。 分别探究相应轴载变量作用下的路面受力情况。具体山区公 路载荷作用区域的网格划分和边界条件如图2、3所示。 


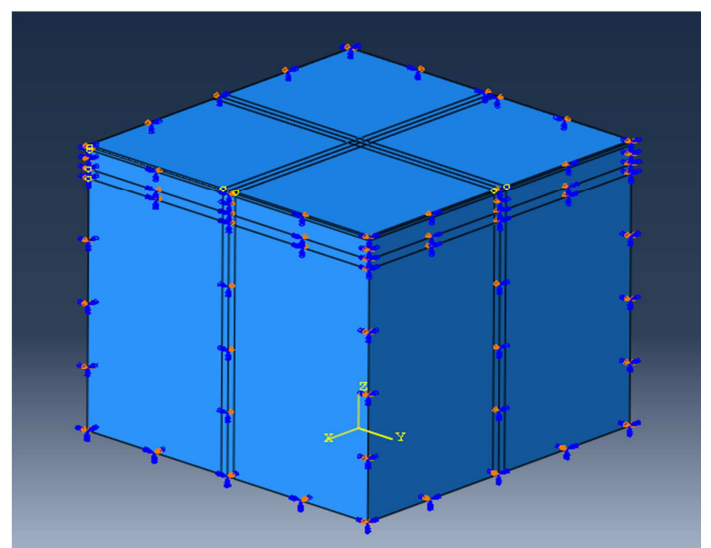

图3 山区公路载荷作用区域的边界条件。

\section{3. 山区公路路面结构力学模拟计算分析}

\section{1. 路面不同深度下各结构层位移值变化分析}

对于不同轴载作用下，分别读取、整理不同结构层的 最大位移值, 由于位移值为负值, 将纵向位移值取绝对值, 最后, 分别得到相应轴载作用下不同深度的最大位移变化 曲线, 相同结构层不同荷载作用下的最大位移变化曲线。 如图4、5所示。

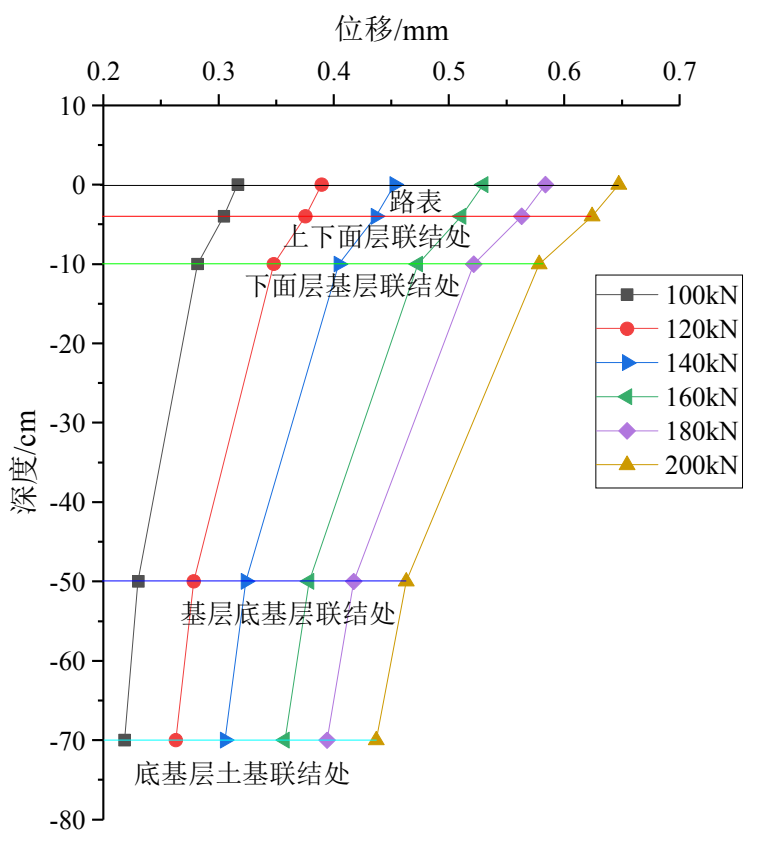

图4 相应轴载作用下不同深度的最大位移变化曲线。

如图4所示，在不同程度荷载作用下各结构层均产生 位移, 而且变化规律一致, 上面层层顶发生位移最大, 位 移随着深度增加而减小。在轴载 $100 \mathrm{kN}$ 时, 上面层层层顶 位移比底基层层底位移大 $44.9 \%$; 轴载 $200 \mathrm{kN}$ 时, 上面层 层顶位移比底基层层底位移大 $48.2 \%$; 由此可知, 轴载对 各结构层位移产生均有影响, 并非仅影响到面层, 对基层 同样作用明显。

如图5所示, 随着荷载的增加, 最大位移也逐渐增加。 与轴载 $100 \mathrm{kN}$ 对应上面层层顶的最大位移相比, 轴载分别
为 $120 \mathrm{kN} 、 140 \mathrm{kN} 、 160 \mathrm{kN} 、 180 \mathrm{kN} 、 200 \mathrm{kN}$ 时，上面层层 顶的最大位移分别增加了 $22.99 \%$ 、 $43.00 \%$ 、 $67.30 \%$ 、 $84.45 \% 、 104.45 \%$, 甚至超过轴载增加比例。因为, 随着 轴载增大, 上面层变形更加严重, 随着深度增加, 最大位 移增加量逐渐减少。由此说明, 轴载增加路面变形严重, 严重影响路面结构, 山区公路路段主要交通量为货车, 需 要严格控制车辆载重, 严禁超载, 防止产生路面病害。

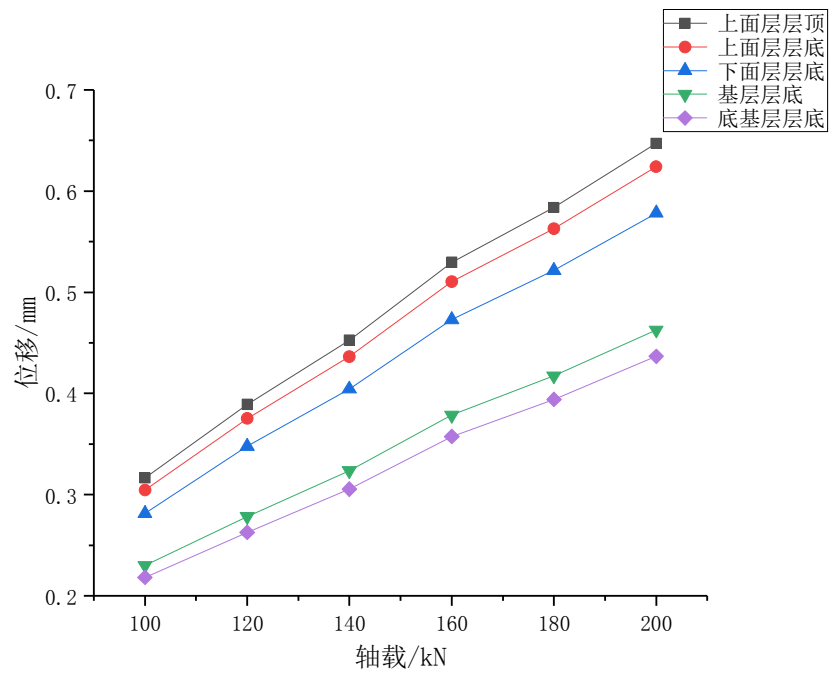

图5 相应结构层不同荷载作用下的最大位移变化曲线。

\section{2. 不同轴载作用下、不同深度路面压应力、压应变的 变化分析}

\subsection{1. 不同轴载作用下、不同深度路面压应力变化分析}

利用有限元模拟分析不同轴载路面压应力变化情况, 分 别得到相应轴载作用下不同深度的压应力变化曲线, 相同结 构层不同轴载作用下的压应力变化曲线。如图6、7所示。

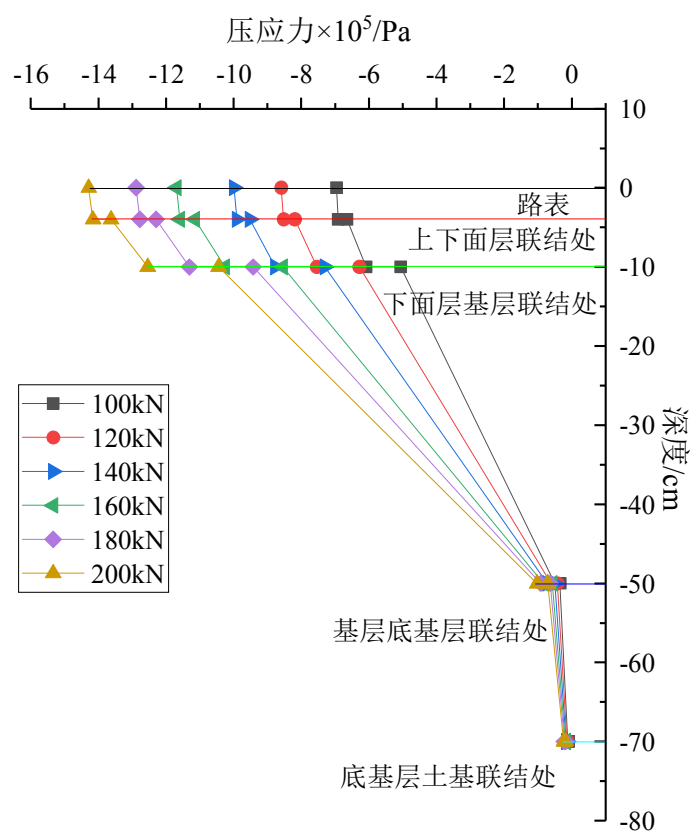

图6 相应轴载作用下不同深度的压应力变化曲线。 


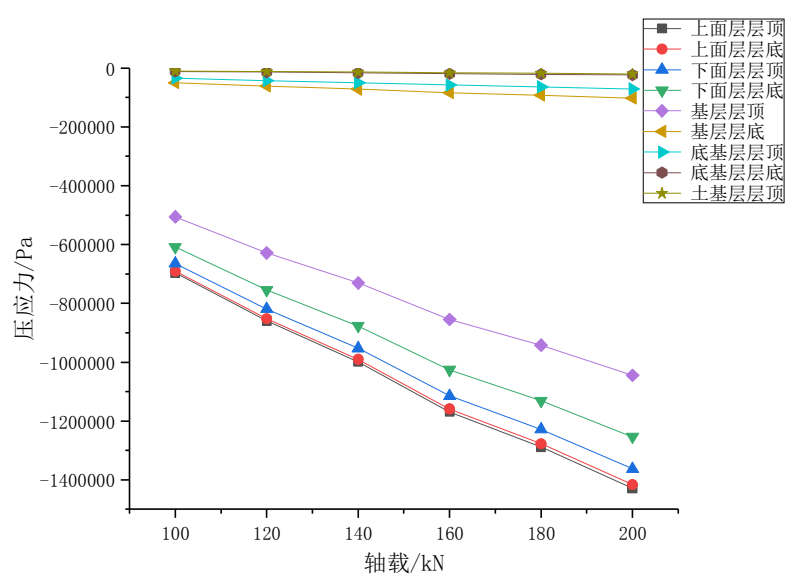

图7 相应结构层不同轴载作用下的压应力变化曲线。

如图6所示，在不同轴载作用下，各结构层层顶和层底 压应力变化规律一致, 最大压应力位于上面层层顶, 上面层 层底最大压应力值与上面层层顶最大压应力值相差较小, 不 同轴载作用下上面层分别下降了 $0.76 \% 、 0.87 \%$ 、 $0.87 \%$ 、 $0.87 \% 、 0.87 \% 、 0.87 \%$, 因为, 整个上面层均承受较大荷载 作用，所以，上面层压应力相差较小。下面层层顶、下面层 层底、基层层顶最大压应力同样相对较大，对于标准轴载 $100 \mathrm{kN}$ 作用下, 与上面层层顶最大压力值相比, 下面层层顶、 下面层层底、基层层顶最大压应力分别下降 $4.5 \%$ 、 $12.6 \%$ 、 $27.3 \%$, 由此可知下面层同样承担较大的压应力。基层层底 压应力相对较小。与相同轴载作用下上面层压应力最大值相 比, 各轴载作用下基层层底压应力最大值均下降了 $92.8 \%$ 以 上, 因为基层刚度较大, 厚度较大, 可以抵抗较大压应力, 因此，底基层和土基承受压应力较小，变形相对较小。

如图7所示，对比相同结构层的压应力，上面层层顶 压应力最大。与标准轴载作用下上面层层顶压应力相比, 在 $120 \mathrm{kN} 、 140 \mathrm{kN} 、 160 \mathrm{kN} 、 180 \mathrm{kN} 、 200 \mathrm{kN}$ 轴载作用下上 面层层顶压应力分别增加了 $23.4 \% 、 43.5 \% 、 67.9 \% 、 85.1 \%$ 、 $105.1 \%$, 因为上面层承担整个轴载, 所以, 轴载对路面结 构压应力影响较大, 随着轴载增加, 压应力增加较大。应 严格控制山区公路通行车辆载重, 尤其是长大纵坡路段。 由此可知, 要提高面层抗压性能, 减少路面坚向变形。 严格控制山区公路路段汽车载重量, 严防路面损害。

\subsection{2. 不同轴载作用下、不同深度路面压应变变化分析}

模拟分析不同轴载路面压应变变化情况, 分别得到相 应轴载作用下不同深度的压应变变化曲线, 相同结构层不 同轴载作用下的压应变变化曲线。如图8、9所示。

如图8所示。不同轴载作用下各结构层的坚向压应变最 大值排序彼此一致, 各结构层竖向压应变最大值从大到小依 次是下面层层顶、下面层层底、上面层层底、基层层顶、上 面层层顶、土基顶、底基层层顶、底基层层底、基层层底。 在一定轴载作用下, 压应变波动变化, 并不是随着深度增加 逐渐降低, 因为各结构层弹性模量彼此不一致, 压应变在各 结构层联结处产生突变, 所以压应变波动变化。压应变突变 主要出现在上下面层联结处和下面层与基层联结处, 由于基 层 (水泥稳定碎石) 厚度较大, 回弹模量较大, 因此压应变 较小。不同轴载作用下, 基层层底压应变相对较小。压应变
最大值出现在下面层层顶, 因为下面层回弹模量相对较小, 因此, 应变值较大, 要提升下面层抗压性能。

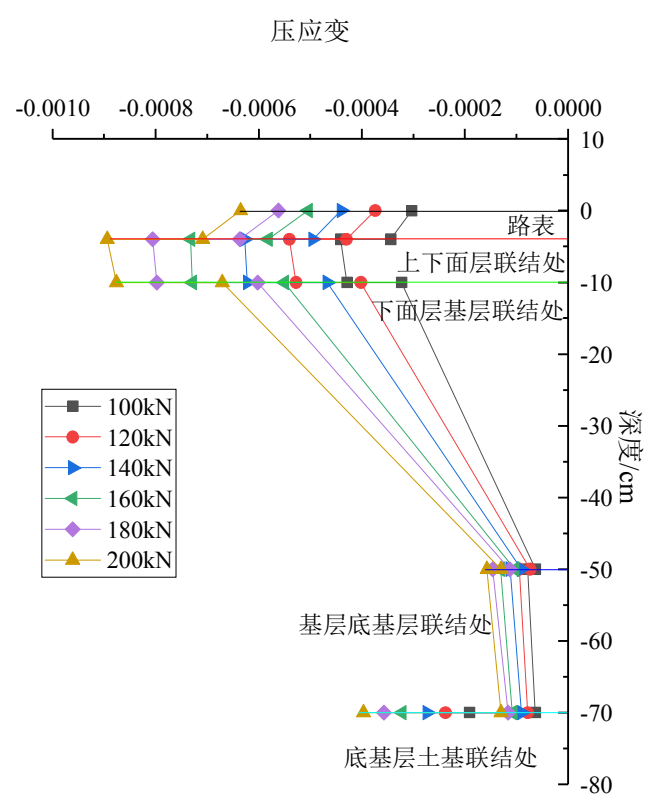

图8 相应轴载作用下不同深度的压应变变化曲线。

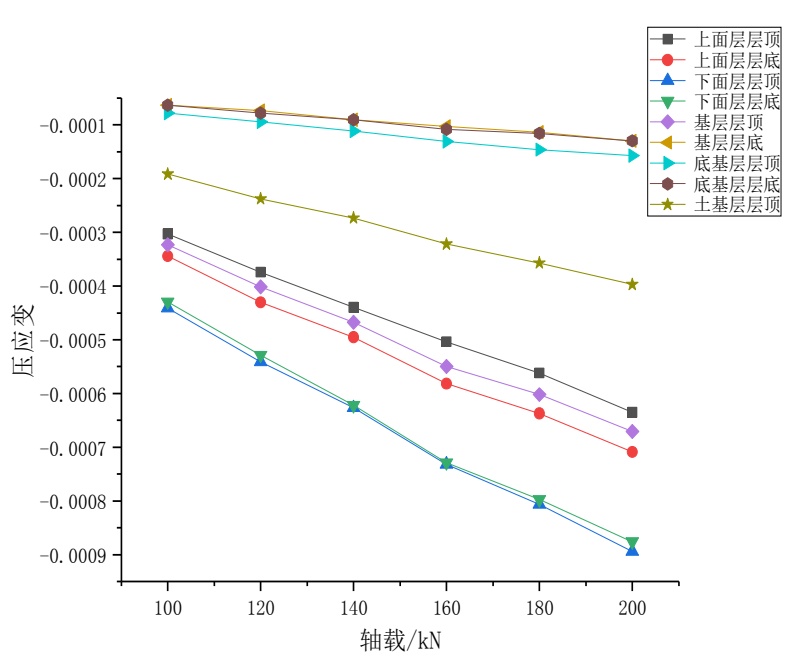

图9 相应结构层不同轴载作用下的压应变变化曲线。

如图9所示。各结构层压应变均随着轴载的增加而增 加, 增加速率较大。路面压应变最大值位于下面层层顶处。 与标准轴载对应的压应变最大值相比, $120 \mathrm{kN} 、 140 \mathrm{kN}$ 、 $160 \mathrm{kN} 、 180 \mathrm{kN} 、 200 \mathrm{kN}$ 对应的压应变最大值分别增加了 $22.7 \% 、 42.2 \% 、 66.0 \% 、 82.9 \% 、 102.9 \%$ ，超过了轴载增 加量, 因为下面层模量相对较小, 极易受到外界轴载影响 而产生形变。

\section{3. 不同轴载作用下、不同深度路面剪应力、剪应变的 变化分析}

\subsection{1. 不同轴载作用下、不同深度路面纵向剪应力变化分 析}

利用有限元模拟分析不同轴载路面纵向剪应力变化 情况, 分别得到相应轴载作用下不同深度的压应力变化曲 
线, 相同结构层不同轴载作用下的纵向剪应力变化曲线。 如图10、11所示。

如图10所示, 与相应轴载作用下不同深度的压应力变 化曲线不同, 最大纵向剪应力并非位于上面层层顶, 随着 深度增加, 纵向剪应力先增加后减小, 并在各结构联结处 发生突变。不同轴载作用下山区公路路面纵向剪应力随深 度变化曲线是一致的, 最大纵向剪切力位于下面层层顶, 其次位于上面层层底, 且下面层层底纵向剪应力也较大, 在与基层联结处发生突变后降低。说明上下面层联结处承 受整个路面结构最大剪切力。对于轴载 $200 \mathrm{kN}$, 与下面层 层顶最大剪应力相比，基层底、底基层顶、土基顶纵向剪 应力分别下降 $86.9 \% 、 96.6 \% 、 98.8 \%$, 说明基层、底基层 承受纵向剪应力很小。因为基层、底基层、土基刚度较大, 抵抗弹性变形能力较大, 所以应力较小。车轮荷载作用于 路面, 纵向剪应力主要发生于沥青面层, 导致沥青混合料 的水平流动, 从而造成车辙、拥包等病害。

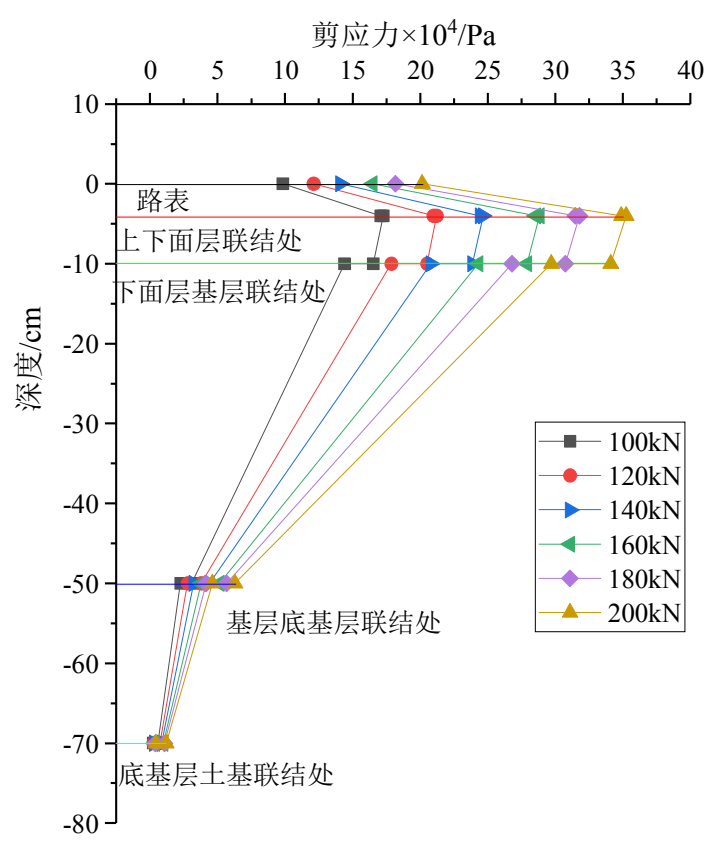

图10 相应轴载作用下不同深度的纵向剪应力变化曲线。

如图11所示, 各结构层纵向剪应力均随着轴载增加而 增加, 与标准轴载 $100 \mathrm{kN}$ 相比, $120 \mathrm{kN} 、 140 \mathrm{kN} 、 160 \mathrm{kN}$ 、 $180 \mathrm{kN} 、 200 \mathrm{kN}$ 轴载作用下，路面结构中最大纵向剪应力 分别增加了 $23.2 \% 、 43.3 \% 、 67.7 \% 、 84.9 \% 、 105.0 \%$, 大 于相应轴载的增加幅度, 轴载增加后, 纵向剪切力增加更 大, 车辙病害会更严重。与标准轴载 $100 \mathrm{kN}$ 相比, 轴载 $200 \mathrm{kN}$ 作用于上面层层顶、上面层层底、下面层层顶、下 面层层底、基层层顶、基层层底、底基层层顶、底基层层 底、土基层顶，其最大纵向剪应力分别增加了 $105.0 \%$ 、 $104.6 \% 、 104.1 \% 、 106.3 \% 、 106.6 \% 、 104.9 \% 、 104.9 \%$ 、 $105.3 \% 、 105.1 \%$, 各结构层增加幅度相差不大, 由此可知, 轴载增加对路面各结构层的影响程度一致, 要严格控制车 辆荷载，防止超载对路面整体结构造成损害。

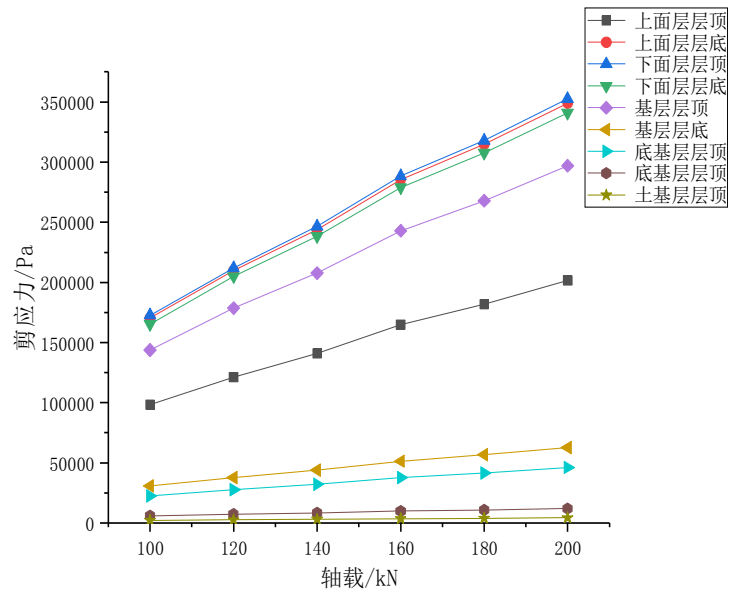

图11 相应结构层不同轴载作用下的纵向剪应力变化曲线。

\subsection{2. 不同轴载作用下、不同深度路面纵向剪应变变化分 析}

模拟分析不同轴载下路面纵向剪应变变化情况, 分别 得到相应轴载作用下不同深度的纵向剪应变变化曲线, 相 同结构层不同轴载作用下的纵向剪应变变化曲线。如图12、 13所示。

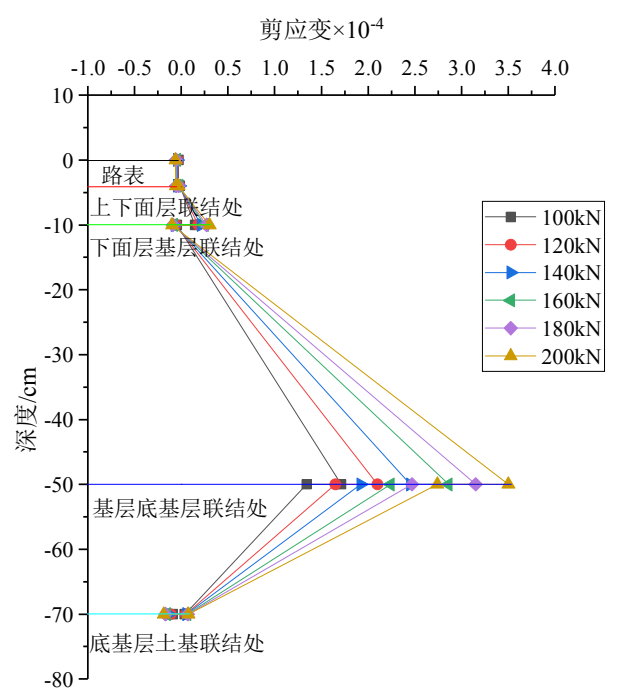

图12 相应轴载作用下不同深度的纵向剪应变变化曲线。

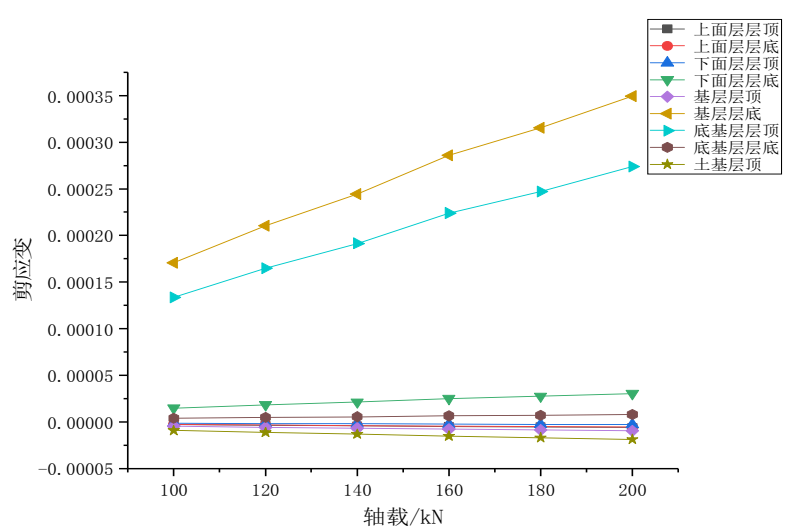

图13 相同结构层不同轴载作用下的纵向剪应变变化曲线。 
如图12所示, 不同轴载作用下山区公路路面不同深度 的纵向剪应变变化趋势是一致的, 剪应变随深度增加出现 正负变化, 在各结构层联结处出现剪应变突变, 最大正向 剪应变位于基层层底, 因为基层刚度较大, 抵抗纵向变形 能力较强, 因此正向剪应变最大, 并且易出现剪切裂缝并 反射到上方。

如图13所示, 随着轴载增加, 剪应变也随之增大, 基 层层底纵向剪应变最大, 与标准轴载 $100 \mathrm{kN}$ 作用下基层层 地的剪应变相比, $120 \mathrm{kN} 、 140 \mathrm{kN} 、 160 \mathrm{kN} 、 180 \mathrm{kN} 、 200 \mathrm{kN}$ 剪应变分别增加了 $21.9 \% 、 41.4 \% 、 63.0 \% 、 78.6 \% 、 94.4 \%$, 应变增加幅度较大, 因此, 严格控制车辆载荷, 防止超载, 引发路面结构损伤。

\subsection{3. 不同轴载作用下、不同深度路面横向剪应力变化分 析}

利用有限元模拟分析不同轴载路面横向剪应力变化 情况, 分别得到相应轴载作用下不同深度的横向剪应力变 化曲线, 相同结构层不同轴载作用下的横向剪应力变化曲 线。如图14、15所示。

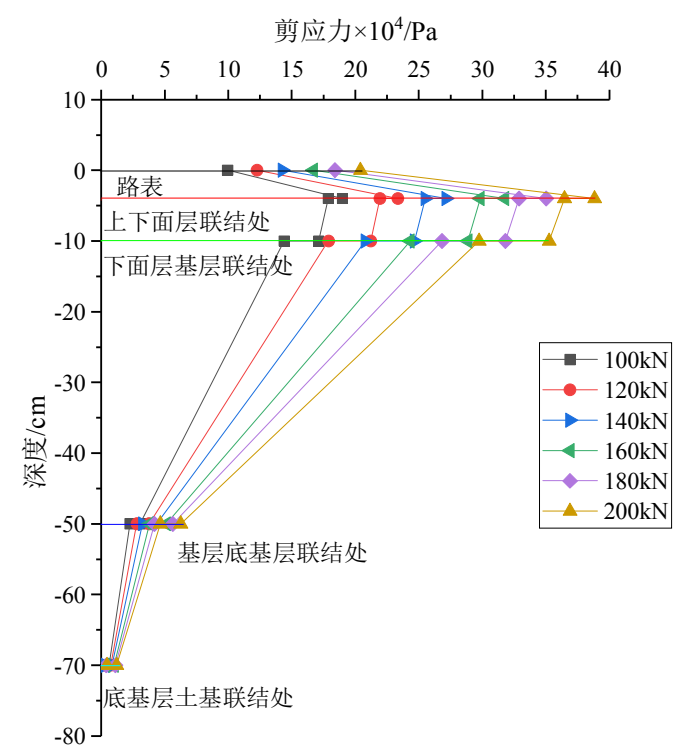

图14 相应轴载作用下不同深度的横向剪应力变化曲线。

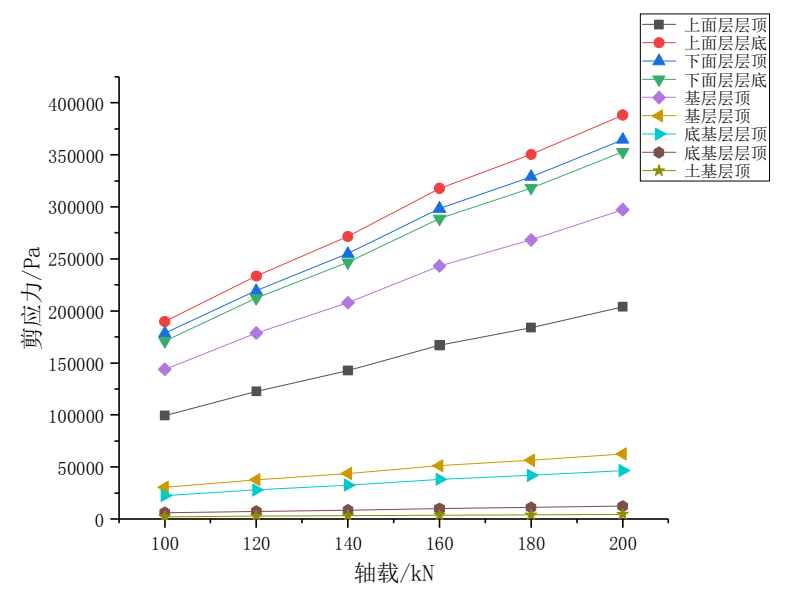

图15 相应结构层不同轴载作用下的横向剪应力变化曲线。
如图14所示, 不同轴载作用下山区公路路面不同深度 的横向剪应力变化趋势是相同的, 和纵向剪应力-深度变 化曲线也是一致的, 均是先增加后减小, 并且在各结构联 结处发生突变, 横向剪应力最大值位于上面层层底, 下面 层层底、下面层层底横向剪应力也较高, 表明上下面层联 结处承受横向剪应力最大, 因为基层、底基层刚度较大, 基层厚度较大, 所以, 抵抗弹性变形的能力较大, 上下面 层联结处横向剪应力最大。

如图 15 所示, 与标准轴载 $100 \mathrm{kN}$ 对应的最大横向剪 应力相比, $120 \mathrm{kN} 、 140 \mathrm{kN} 、 160 \mathrm{kN} 、 180 \mathrm{kN} 、 200 \mathrm{kN}$ 作 用下的最大横向剪应力分别增加 $23.1 \% 、 43.1 \% 、 67.4 \%$ 、 $84.6 \% 、 104.6 \%$, 和纵向剪应力增加幅度相近, 由此可 知, 轴载增加使得路面整体的结构受力均有所增加, 要 严格控制山区公路通行车辆的载货量, 防止路面结构发 生剪切破坏。

\section{4. 结论}

轴载对各结构层位移均产生影响。变化规律彼此一致, 上面层层顶产生位移最大, 位移随着深度增加而减小。轴 载增加, 路面变形越加严重。

在轴载作用下, 上面层、下面层同样承担较大的压应 力, 其他结构层压应力较小。下面层压应变较大, 各结构 层模量不一, 因此压应变波动变化。轴载增加, 压应力、 压应变随之增加。应严控车辆超载, 防止路面病害产生。

在轴载作用下, 纵向剪应力主要集中于面层, 纵向剪 应变在各结构层发生突变, 荷载增加, 纵向剪应力、纵向 剪应变随之增加。横向剪应力主要集中于面层, 在各结构 层发生突变, 先增加后减小。随着载荷增加, 剪应力、剪 应变随之增加。注重提升面层抗压性能, 增加各结构层彼 此粘接性能。

本文得到了不同轴载作用下的道路结构变形和受 力, 但是在不同车速下道路结构的变形受力没有进行考 虑, 后续工作对不同车速下的道路结构的变形和受力进 行研究。

\section{致谢}

本文为国家重点研发计划重点专项 （2017YFC0805404）、国家安全生产监督总局科技项目 （hebei-0009-2017AQ）的阶段性成果之一。

\section{参考文献}

[1] WangY, LuY J, Si C D, et al. Finite element analysis for rutting prediction of asphalt concrete pavement under moving wheel load [J]. International Journal of Simulation Modelling, 2017, 16 (2): 229-240.

[2] Gu F, Luo X, West R C, et al. Energy-based crack initiation model for load-related top-down cracking in asphalt pavement [J]. Construction and Building Materials, 2018, 159 (20): 587-597. 
[3] Yang S R, Chang J R. Using genetic programming to predict plastic strain in subgrade soils under repeated loading[J]. Journal of testing and evaluation, 2017, 45 (1): 85-93.

[4] Yanov D V, Zelepugin S A. Road pavement design using the finite element method[C]. Tomsk; VII International Conference on Current Issues of Continuum Mechanics and Celestial Mechanics, 2018. 26-28.

[5] Hu XD, Faruk A N M, Zhang J, et al. Effects of tire inclination (turning traffic) and dynamic loading on the pavement stress-strain responses using 3-D finite element modeling $[\mathrm{J}]$. International Journal of Pavement Research and Technology, 2017, 10 (4): 304-314.

[6] Ai C F, Ali R, Xiao C, et al. Analysis of measured strain response of asphalt pavements and relevant prediction models $[\mathrm{J}]$. International Journal of Pavement Engineering, 2017, 18 (12): 1089-1097.

[7] Cheng H L, Liu L P, Sun L J, et al. Comparative analysis of strain-pulse-based loading frequencies for three types of asphalt pavements via field tests with moving truck axle loading [J], Construction and Building Materials, 2020, 247 : 118519 .

[8] 李海滨,赵海生,沙爱民,等.基于控制裂缝和车辙的半刚性基 层沥青路面力学行为分析[J].武汉理工大学学报,2014,36(4): $65-72$ 。
[9] 周正峰,苗禄伟,孙超.基于应变的路基工作区深度及其影响 因素分析 [J]. 武汉理工大学学报 (交通科学与工程 版),2016,40(1):41-44。

[10] 王志红,杨旭红.基于重载及水平荷载的不同类型沥青路面 力学响应分析 [J].公路,2019,(12):21-25。

[11] 阮鹿鸣.山区公路长大纵坡段沥青路面结构疲劳损伤研究 [D].重庆:重庆交通大学,2018。

[12] 王浩,陈华金辁,叶丹燕,等.基于正交试验的沥青路面结构力学 响应参数敏感性分析[J].中外公路,2017,37(5):47-50。

[13] 贾晓东,梁乃兴,赵毅,等.水-温-荷载耦合作用下沥青路面疲 劳寿命预估[J].公路,2019,(11):193-198。

[14] 桑伟.长大纵坡沥青路面疲劳开裂分析[D].兰州:兰州交通 大学,2018。

[15] 范永根,朱春东,付欣.高温重载耦合作用下沥青路面剪应力 分析[J].山西建筑,2020,46(1):9-11。

[16] 周陶宏.重载作用下沥青路面结构力学响应及损伤分析 [J]. 工程建设与设计,2019,0(3):87-90。 